\title{
Sistem Pendukung Keputusan Penilaian Calon Supervisor Pada PT.Petnesia Resindo Dengan Metode Simple Additive Weighting (Saw)
}

\author{
Agung Triayudi ${ }^{1}$ Ulwi Sya'bana $^{2}$ \\ Program Studi Teknik Informatika, Fakultas Teknologi Informasi \\ Universitas Serang Raya \\ ${ }^{1}$ agung.triayudi@gmail.com \\ ${ }^{2}$ ulwisyabana@gmail.com
}

\begin{abstract}
Sebagai elemen dalam perusahaan yang sangat penting adalah Sumber Daya Manusia (SDM). Pengelolaan Sumber Daya Manusia dari suatu perusahaan sangat mempengaruhi banyak aspek penentu keberhasilan kinerja dari perusahaan tersebut. Jika kinerja perusahaan dapat terorganisir, maka segala aspek yang ada di dalam perusahaan tersebut dapat berjalan dengan baik. Sebab sumber daya manusia (SDM) merupakan faktor yang berperan penting dalam penentuan keberhasilan sumber daya manusia yaitu karyawan. Sebagai salah satu upaya dalam meningkatkan kualitas karyawan, PT. Petnesia Resindo (PNR) membuat suatu program yang bertujuan membantu dalam peningkatan potensi karyawan agar Sumber Daya Manusia (SDM) yang terdapat di perusahaan tersebut dapat dioptimalkan sesuai dengan yang di harapkan oleh PT. Petnesia Resindo (PNR). Masalah yang terdapat pada PT. Petnesia Resindo (PNR) tersebut, karena belum adanya aplikasi sistem penilaian calon supervisor yang menggunakan pengukuran bedasarkan aspek dan kriteria-kriteria yang diinginkan serta di capai oleh perusahaan tersebut. Untuk memecahkan masalah di PT. Petnesia Resindo (PNR) dibutuhkan suatu aplikasi sistem pendukung keputusan penilaian calon supervisor yang dapat mengetahui potensi pada setiap karyawan yang ada di perusahaan tersebut secara real dan objektif dengan menggunakan metode Simple Additive Weighting (SAW).
\end{abstract}

Kata kunci : Supervisor, Sistem Pendukung Keputusan, Simple Additive Weighting (SAW).

\section{PENDAHULUAN}

\subsection{Latar Belakang}

PT. Petnesia Resindo (PNR) merupakan perusahaan yang memproduksi dan memasarkan Polyethylene Terephatalate (PET) Resin yang berkualitas tinggi. Produk utamanya, chip PET, adalah bahan baku pembuatan botol dan kemasan plastik yang aman untuk dijadikan kemasan makanan dan minuman, agar senantiasa memiliki ke unggulan bersaing, terutama dalam pasar global yang di tuntut untuk dapat mengantisipasi perubahan-perubahan yang demikian cepat dan dinamis agar dapat bertahan hidup dan dapat meningkatkan efesiensi dan produktivitas perusahaan melalui sumber daya manusia (SDM). Sebagai elemen dalam perusahaan yang sangat penting adalah Sumber Daya Manusia (SDM). Pengelolaan Sumber Daya Manusia dari suatu perusahaan sangat mempengaruhi banyak aspek penentu keberhasilan dari perusahaan tersebut. Jika kinerja perusahaan dapat terorganisir, maka segala aspek yang ada di dalam perusahaan tersebut dapat berjalan dengan baik seperti penilaian calon supervisor. Sebab sumber daya manusia (SDM) merupakan faktor yang berperan penting dalam penentuan keberhasilan dalam hal kualitas karyawan. Dengan kata lain sumber daya manusia (SDM) dapat mengoptimalkan keunggulan perusahaan dalam meningkatkan kualitas perusahaan.

Sebagai salah satu upaya dalam meningkatkan kualitas karyawan yang ingin menjadi calon supervisor, PT. Petnesia Resindo (PNR) membuat suatu program yang bertujuan membantu dalam peningkatan calon supervisor agar Sumber Daya Manusia (SDM) yang terdapat diperusahaan tersebut dapat dioptimalkan sesuai dengan yang di harapkan oleh PT. Petnesia Resindo (PNR).

Masalah yang terdapat pada PT. Petnesia Resindo (PNR) tersebut, karena belum adanya program penilaian calon supervisor yang menggunakan pengukuran bedasarkan aspek dan kriteria-kriteria yang diinginkan serta di capai oleh perusahaan tersebut. Sehingga dalam proses penilaian terpilihnya supervisor hanya berpatokan pada prilaku secara langsung yang di anggap senior, namun pada kenyataannya tidak bisa memberikan 
konstribusi lebih pada perusahaan dan tidak ada metode khusus yang digunakan dalam penilaian calon supervisor, sehingga penilaian tidak tepat sasaran. Disamping itu juga dalam proses perhitungan pada setiap calon supervisor yaitu karyawan juga memakan waktu lama karena tidak adanya suatu aplikasi penilaian calon supervisor.

Untuk memecahkan masalah di PT. Petnesia Resindo (PNR) dibutuhkan suatu sistem pendukung keputusan penilaian calon supervisor yang dapat mengetahui informasi yang mendukung pada setiap karyawan yang ingin menjadi calon supervisor yang ada di perusahaan tersebut secara real dan objektif.

Dengan adanya sistem pendukung keputusan penilaian calon supervisor pada PT. Petnesia Resindo (PNR) diharapkan dapat memberikan hasil penilaian calon supervisor yang lebih objektif serta membantu perhitungan nilai terseleksinya calon supervisor yaitu karyawan yang tepat dan akurat berdasarkan kompetensi secara efisien dan objektif. Karena pada penilaian ini mengguakan perhitungan dan pencocokan berdasarkan Kriteria-kriteria penilaian tersebut yang ditujukan kepada karyawan PT. Petnesia Resindo (PNR). Dalam sistem pendukung keputusan yang akan dibangun kriteriakriteria yang telah ditentukan perusahaan tersebut, akan dihitung dengan menggunakan metode Simple Additive Weighting (SAW). Metode SAW sering juga dikenal istilah metode penjumlahan terbobot. Konsep dasar metode SAW adalah mencari penjumlahan terbobot dari rating kinerja pada setiap alternatif pada semua atribut selanjutkan hasil penilaian akan diurutkan berdasarkan nilai tertinggi ke nilai terendah.

\section{METODE PENELITIAN}

\section{Definisi Sistem}

Menurut Rahmat (2004 : 11) "Sistem berasal dari bahsa latin (systema) dan bahasa yunani (sustema) adalah suatu kesatuan yang terdiri dari komponen atau elemen yang dihubungkan bersama untuk memudahkan aliran informasi, materi atau energi untuk mencapai suatu tujuan". Istilah ini sering dipergunakan untuk menggambarkan suatu set entitas yang berinteraksi, dimana suatu model matematika seringkali bisa dibuat.

\section{Sistem Pendukung Keputusan}

Konsep awal sistem pendukung keputusan dikenalkan pertama kali oleh Scott Morton pada awal tahun 1970-an. Ia mendefinisikan sistem pendukung keputusan sebagai sistem berbasis komputer interaktif, yang membantu para pengambil keputusan untuk menggunakan data dan berbagai model untuk memecahkan masalah-masalah tidak terstruktur.

Menurut Little (1970:137) "sistem pendukung keputusan (DSS) merupakan sekumpulan prosedur berbasis model untuk data pemprosesan dan penilaian guna membantu para manajer mengambil keputusan". "Dia menyatakan bahwa untuk sukses, sistem tersebut haruslah sederhana, cepat, mudah di kontrol, adatif, lengkap dengan isu-isu penting dan mudah berkomunikasi.

\section{Definisi Penilaian Kinerja}

Menurut Rivai dan Basri (2004) "Kinerja adalah hasil seseorang secara keseluruhan selama periode tertentu di dalam melaksanakan tugas, seperti standar hasil kerja, target atau sasaran atau kriteria yang telah ditentukan terlebih dahulu dan telah disepakati bersama”.

\section{Metode Simple Additive Weighting (SAW)}

Metode Simple Addititive Weighting (SAW) sering juga dikenal sebagai metode penjumlahan terbobot. Konsep dasar metode SAW adalah mencari penjumlahan terbobot dari rating kinerja pada setiap alternatif pada semua atribut (Fishburn, 1967) (MacCrimmon, 1968). Metode SAW membutuhkan proses normalisasi matriks keputusan (X) ke suatu skala yang dapat diperbandingkan dengan semua rating alternatif yang ada ( Kusumadewi, dkk (2006:5).

$$
r_{i j}= \begin{cases}\frac{x_{i j}}{\operatorname{Max}_{i}\left(x_{i j}\right)} & \text { Jika j adalah kriteria keuntungan (benefit) } \\ \frac{\operatorname{Min}_{i}\left(x_{i j}\right)}{x_{i j}} & \text { Jika jadalah kriteria biaya (cost) }\end{cases}
$$

Dimana :

$\mathrm{R}_{\mathrm{ij}} \quad$ : Rating

kinerja ternormalisasi

Maxi : Nilai maksimum dari setiap baris dan

Mini $_{\mathrm{i}}$ : Nilai minimum dari setiap baris dan kolom

$\mathrm{X}_{\mathrm{ij}} \quad$ : Baris dan kolom dari matriks

Dimana $r_{i j}$ adalah rating kinerja ternormalisasi dari alternatif $\mathrm{A}_{\mathrm{i}}$ pada atribut $\mathrm{C}_{\mathrm{ji}}=1,2, \ldots, \mathrm{m}$ dan $\mathrm{j}$ $=1,2, \ldots, \mathrm{m}$. Nilai preferensi alternatif (Vi) diberikan sebagai :

$$
\mathrm{V}_{\mathrm{i}}=\sum_{j=1}^{n} w_{j} \boldsymbol{r}_{i j}
$$

Dimana :

$\mathrm{Vi}$ : Nilai Akhir Alternatif

Wi : Bobot yang telah ditentukan

Rij : Normalisasi matriks

Nilai V yang lebih besar, mengindikasikan bahwa alternatif Ai lebih terpilih.

Langkah-langkah penyelesaiannya sebagai berikut :

1. Menentukan kriteria-kriteria yang akan dijadikan acuan dalam mengambilan keputusan, yaitu $\mathrm{Ci}$.

2. Menentukan rating kecocokan setiap 
alternatif pada setiap kriteria.

3. Membuat matriks keputusan berdasarkan kriteria (Ci), kemudian melakukan normalisasi matriks berdasarkan persamaan yang disesuaikan dengan jenis atribut (atribut keuntungan ataupun atribut biaya) sehingga diperoleh matriks ternormalisasi $\mathrm{R}$.

4. Hasil akhir diperoleh dari proses perankingan yaitu penjumlahan

5. Dari perkalian matriks ternormalisasi $\mathrm{R}$ dengan vector bobot sehingga diperoleh nilai terbesar yang dipilih sebagai alternatif terbaik (Ai) sebagai solusi.

\section{HASIL DAN PEMBAHASAN}

\subsection{PERANCANGAN SISTEM SECARA UMUM}

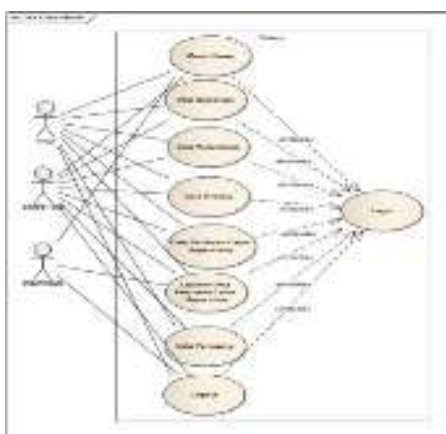

Gambar 3.1 Usecase

Tabel 1 : Kriteria Calon Supervisor

\begin{tabular}{|l|l|}
\hline Kriteria & Keterangan \\
\hline C1 & Keahlian \\
\hline C2 & Nilai Psikotes \\
\hline C3 & Nilai K.Bahasa Asing \\
\hline C4 & Kepribadian \\
\hline C5 & Masa Kerja \\
\hline
\end{tabular}

Tabel 2 : Alternatif Calon Supervisor

\begin{tabular}{|l|l|l|l|l|l|}
\hline $\begin{array}{l}\text { Nama } \\
\text { Karyawan }\end{array}$ & \multicolumn{5}{|c|}{ Kriteria } \\
\hline Rohmat & 90 & 70 & 70 & 85 & 30 \\
\hline Pujianto & 85 & 85 & 90 & 70 & 20 \\
\hline Dermawan & 70 & 75 & 75 & 70 & 42 \\
\hline Kurniawan & 80 & 80 & 60 & 85 & 35 \\
\hline
\end{tabular}

Dengan bobot sebagai berikut :

$$
\mathrm{W}=(30,25,20,15,10)
$$

1. Untuk alternatif A1 dengan nama Rohmat, dengan nilai normalisasi :

$$
\begin{aligned}
& \mathrm{R} 11=\frac{90}{\operatorname{Max} 90 ; 85 ; 70 ; 80}=\frac{90}{90}=1 \\
& \mathrm{R} 12=\frac{70}{\operatorname{Max} 70 ; 85 ; 75 ; 80}=\frac{70}{85}=0,82 \\
& \mathrm{R} 13=\frac{70}{\operatorname{Max} 70 ; 90 ; 75 ; 60}=\frac{70}{90}=0,77 \\
& \mathrm{R} 14=\frac{85}{\operatorname{Max} 85 ; 70 ; 70 ; 85}=\frac{85}{85}=1 \\
& \mathrm{R} 15=\frac{30}{\operatorname{Max} 30 ; 20 ; 42 ; 35}=\frac{30}{42}=0,71
\end{aligned}
$$

2. Untuk alternatif A2 dengan nama Pujianto, dengan nilai normalisasi :

$$
\begin{aligned}
\mathrm{R} 21 & =\frac{85}{\operatorname{Max} 90 ; 75 ; 70 ; 80}=\frac{85}{90}=0,94 \\
\mathrm{R} 22 & =\frac{85}{\operatorname{Max} 70 ; 85 ; 75 ; 80}=\frac{85}{85}=1 \\
\mathrm{R} 23 & =\frac{90}{\operatorname{Max} 70 ; 90 ; 75 ; 60}=\frac{90}{90}=1 \\
\mathrm{R} 24 & =\frac{70}{\operatorname{Max} 85 ; 70 ; 70 ; 85}=\frac{70}{85}=0,82 \\
\mathrm{R} 25= & \frac{20}{\operatorname{Max} 30 ; 20 ; 42 ; 35}=\frac{20}{42}=0,48
\end{aligned}
$$

3. Untuk alternatif A3 dengan nama Dermawan, dengan nilai normalisasi :

$$
\begin{aligned}
& \mathrm{R} 31=\frac{70}{\operatorname{Max} 90 ; 75 ; 70 ; 80}=\frac{70}{90}=0,77 \\
& \mathrm{R} 32=\frac{75}{\operatorname{Max} 70 ; 85 ; 75 ; 80}=\frac{75}{85}=0,88 \\
& \mathrm{R} 33=\frac{75}{\operatorname{Max} 70 ; 90 ; 75 ; 60}=\frac{75}{85}=0,83 \\
& \mathrm{R} 34=\frac{70}{\operatorname{Max} 85 ; 70 ; 70 ; 85}=\frac{70}{85}=0,82 \\
& \mathrm{R} 35=\frac{42}{\operatorname{Max} 30 ; 20 ; 42 ; 35}=\frac{42}{42}=1
\end{aligned}
$$

4. Untuk alternatif A4 dengan nama Kurniawan, dengan nilai normalisasi :

$$
\mathrm{R} 41=\frac{80}{\operatorname{Max} 90 ; 75 ; 70 ; 80}=\frac{80}{90}=0,88
$$




$$
\begin{aligned}
& \mathrm{R} 42=\frac{80}{\operatorname{Max} 70 ; 85 ; 75 ; 80}=\frac{80}{85}=0,94 \\
& \mathrm{R} 43=\frac{60}{\operatorname{Max} 70 ; 90 ; 75 ; 60}=\frac{60}{85}=0,66 \\
& \mathrm{R} 44=\frac{85}{\operatorname{Max} 85 ; 70 ; 70 ; 85}=\frac{85}{85}=1 \\
& \mathrm{R} 45=\frac{75}{\operatorname{Max} 30 ; 20 ; 42 ; 35}=\frac{35}{42}=0,83
\end{aligned}
$$

a. Form Login

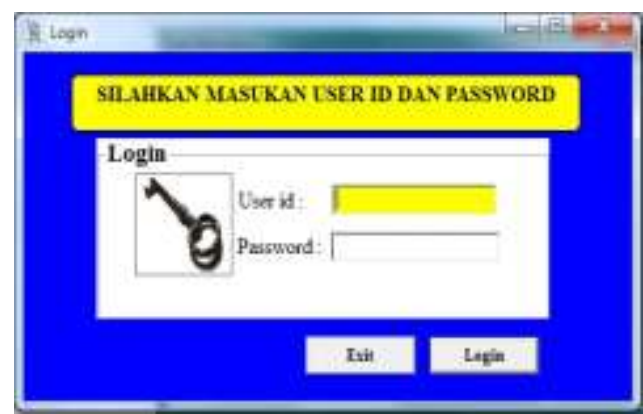

Gambar 3.2 Login

\section{b. Form Menu Utama}

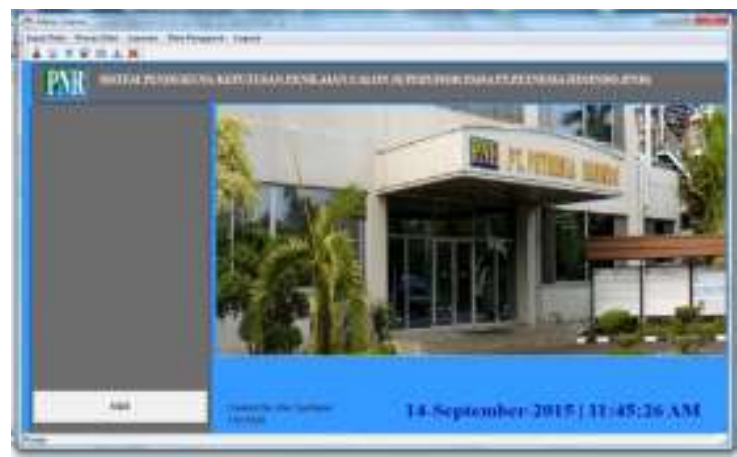

Gambar 3.3 Menu Utama

\section{c. Form Data Karyawan}

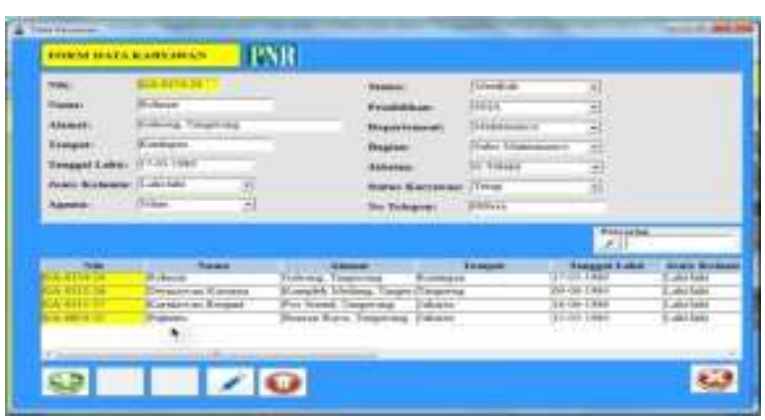

Gambar 3.4 Data Karyawan d. Form data peruntukan

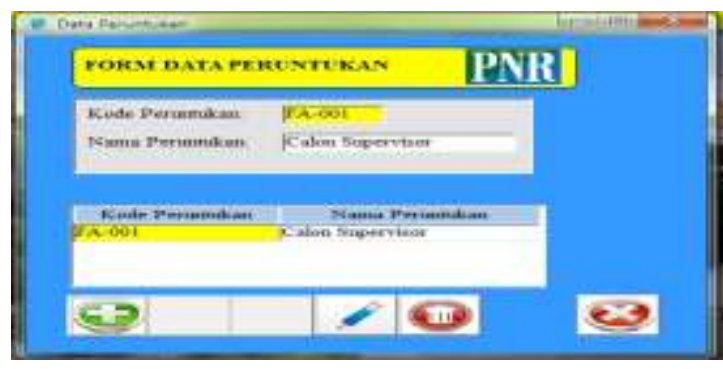

Gambar 3.5 Data Peruntukan

e. Form penilaian calon supervisor

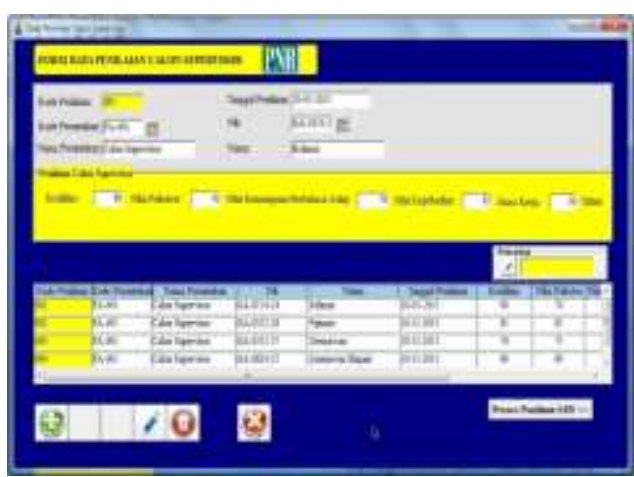

Gambar 3.6 Penilaian Calon Supervisor

f. Form Proses Penilaian Calon Supervisor

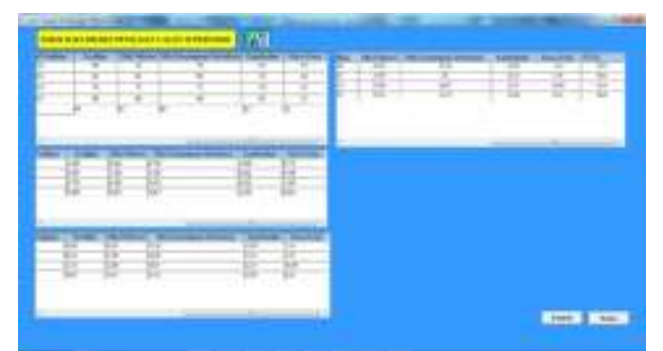

Gambar 3.7 Proses Penilaian Calon Supervisior

g. Form Laporan Penilaian Calon Supervisor Proses SAW

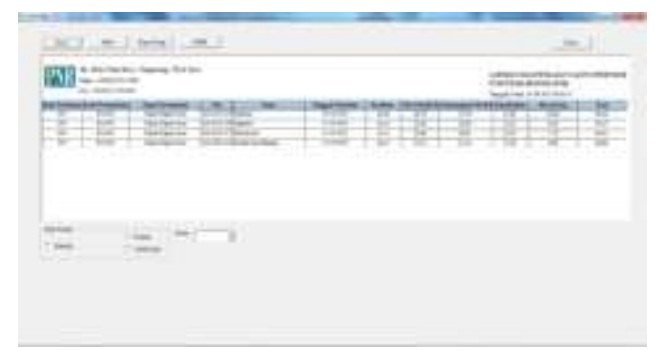

Gambar 3.8 Laporan Penilaian Calon Supervisor 


\section{KESIMPULAN DAN SARAN}

Pembuatan Sistem Pendukung Keputusan Penilaian Calon Supervisor Pada PT Petnesia Resindo (PNR) ini, untuk melakukan perhitungan penilaian calon supervisor dengan hasil perangkingan telah berhasil di bangun. Sistem yang telah dibuat mengacu pada rumusan masalah yang ada yaitu sistem dapat melakukan penilaian calon supervisor sesuai ketentuan dengan melakukan perhitungan berdasarkan metode SAW (Simple Additive Weighting). Beberapa kesimpulan yang dapat dijabarkan sebagai berikut:

1. Sistem ini bertujuan untuk membantu dalam melakukan penilaian calon supervisor.

2. Perhitungan pada sistem untuk melakukan penyeleksian menggunakan metode simple additive weighthing

3. Tahap - tahap proses pengembangan sistem dalam penelitian ini adalah identifikasi masalah, analisis sistem, perancangan, pengujian dan implementasi.

4. Hasil dari perhitungan sistem merupakan perangkingan nilai tertinggi ke rendah dan nilai tertinggi merupakan hasil untuk memperoleh calon supervisor.

5. Sistem yang dibangun hanya sebagai alat bantu untuk memberikan informasi kepada pimpinan sebagai bahan pertimbangan dalam mengambil keputusan calon supervisor.

\section{SARAN}

Setelah berusaha dengan maksimal untuk menyelesaikan skripsi ini, maka perkenankanlah penulis untuk untuk memberikan saran seperti apa yang penulis lihat selama penulis melakukan riset, yang sekiranya dapat membantu penggunaan sistem pendukung pengambilan keputusan penilaian calon supervisor pada PT. Petnesia Resindo (PNR). Saransaran tersebut diantaranya adalah :

1. Setelah menggunakan sistem pendukung pengambilan keputusan penilaian calon supervisor ini, ketelitian dalam menginput data juga sangat diperlukan agar data yang direkam merupakan salinan data dari dokumen atau sumber.

2. Untuk memaksimalkan pemakaian dan kelancaran penggunaan aplikasi, diharapkan pengguna dapat memahami kegunaan aplikasi tersebut.

Demikianlah saran-saran dari penulis agar sistem pendukung pengambilan keputusan penilaian calon supervisor di PT. Petnesia Resindo dapat maksimal dalam penggunaannya.

\section{REFERENCES}

[1] Aryo Edgar Fredika (2012), Sistem Pendukung Keputusan Penilaian Kinerja Karyawan Kontrak Pada Kantor Perustakan Dan Arsip Kota Semarang).Semarang

[2] Emil Widyarachmawati (2011), Rancang Bangun Sistem Pendukung Keputusan Penilaian Kinerja Karyawan Dengan Menggunakan Metode Simple Additive Weighting (SAW) Studi Kasus : PT. Persero Angkasa Pura 1 Bandara Udara Juanda Surabaya. Surabaya

[3] Endro Siprianus Sri Widodo, Lutfi Septia, Solikin, (2011). Sistem Pendukunng Keputusan Penilaian Kinerja Karyawan Dengan Menggunakan Metode Simple Additive Weighting (SAW) pada PT.Indonesia Steel Tube Work. STIMIK Himsyah

[4] Hartati Sri. Analisa Sistem Informasi. AKMI Batu Raja

[5] Hendri Mandala Putra (2012), Sistem Pendukung Keputusan Pemilihan Karyawan Berprestasi Di Pertamina Pengapon Semarang Dengan Metode Simple Additive Weighting (SAW).Semarang

[6] Irfan Subakti (2002).Sistem Pendukung Keputusan.Surabaya

[7] M. Sulaiman Silalahi (2013), Sistem Pendukung Keputusan Kenaikan Jabatan Dengan Menggunakan Metode Simple Additive Weighting (SAW) Studi Kasus : Gapeksindo Medan. Medan

[8] Mangkunegara Prabu Anwar (2007). Evaluasi Kinerja SDM.Bandung

[9] Turban Efrain, Aronson E Jay, Liang Peng Ting (2005), Decision Support Systems and Intelliegent Systems. Yogyakarta 
